\title{
BMJ Open Implications of a travel connectivity- based approach for infectious disease transmission risks in Oceania
}

\author{
Angela Cadavid Restrepo (10 , ${ }^{1,2}$ Luis Furuya-Kanamori, ${ }^{2,3}$ Helen Mayfield, ${ }^{1,2}$ \\ Eric Nilles, ${ }^{4,5}$ Colleen L Lau ${ }^{1,2}$
}

To cite: Cadavid Restrepo A, Furuya-Kanamori L, Mayfield $\mathrm{H}$, et al. Implications of a travel connectivity-based approach for infectious disease transmission risks in Oceania. BMJ Open 2021;11:e046206. doi:10.1136/ bmjopen-2020-046206

- Prepublication history and additional supplemental material for this paper are available online. To view these files, please visit the journal online. (http://dx.doi.org/10.1136/ bmjopen-2020-046206).

Received 23 October 2020 Accepted 18 July 2021

Check for updates

(c) Author(s) (or their employer(s)) 2021. Re-use permitted under CC BY-NC. No commercial re-use. See rights and permissions. Published by BMJ.

${ }^{1}$ School of Public Health, The University of Queensland, Faculty of Medicine, Brisbane, Queensland, Australia

${ }^{2}$ Research School of Population Health, College of Health and Medicine, The Australian National University, Canberra, Australian Capital Territory, Australia

${ }^{3} U Q$ Centre for Clinical Research, Faculty of Medicine, The University of Queensland, Brisbane, Queensland, Australia ${ }^{4}$ Harvard Medical Shool, Harvard University, Cambridge, Massachusetts, USA

${ }^{5}$ Harvard Humanitarian Initiative, Harvard University, Cambridge, Massachusetts, USA

Correspondence to Dr Angela Cadavid Restrepo; a.cadavidrestrepo@uq.edu.au

\section{ABSTRACT}

Introduction The increase in international travel brought about by globalisation has enabled the rapid spread of emerging pathogens with epidemic and pandemic potential. While travel connectivity-based assessments may help understand patterns of travel network-mediated epidemics, such approaches are rarely carried out in sufficient detail for Oceania where air travel is the dominant method of transportation between countries. Design Travel data from the Australian Bureau of Statistics, Stats NZ and the United Nations World Tourism Organization websites were used to calculate travel volumes in 2018 within Oceania and between Oceania and the rest of the world. The Infectious Disease Vulnerability Index (IDVI) was incorporated into the analysis as an indicator of each country's capacity to contain an outbreak. Travel networks were developed to assess the spread of infectious diseases (1) into and from Oceania, (2) within Oceania and (3) between each of the Pacific Island Countries and Territories (PICTs) and their most connected countries.

Results Oceania was highly connected to countries in Asia, Europe and North America. Australia, New Zealand and several PICTs were highly connected to the USA and the UK (least vulnerable countries for outbreaks based on the IDVI), and to China (intermediate low vulnerable country). High variability was also observed between the PICTs in the geographical distribution of their international connections. The PICTs with the highest number of international connections were Fiji, French Polynesia, Guam and Papua New Guinea.

Conclusion Travel connectivity assessments may help to accurately stratify the risk of infectious disease importation and outbreaks in countries depending on disease transmission in other parts of the world. This information is essential to track future requirements for scaling up and targeting outbreak surveillance and control strategies in Oceania.

\section{INTRODUCTION}

Cross-border and cross-continental travel are principal driving forces of the importation, dissemination and exportation of pathogens. ${ }^{1}$ With globalisation, the ease of international travel has enabled the rapid spread of emerging and newly identified pathogens that have epidemic and pandemic potential. ${ }^{1}$ The geographical expansion and reported

\section{Strengths and limitations of this study}

- The study helped to identify countries that are high priority for funding and technical support if an outbreak emerges in different countries around the world or within Oceania.

- Data involved travel volumes under normal travel conditions and a measure of each country's vulnerability and capability to respond to epidemics.

- This travel connectivity-based approach can be updated easily as travel patterns and volumes evolve.

- Visual representations and interactive material were produced to characterise the risks of infectious disease transmission into and within the continent of Oceania.

- Data were collected based on nationality rather than the passengers' country of residence.

outbreaks of dengue, Chikungunya and Zika viruses (ZIKVs) in several regions including Oceania demonstrates the critical association between growing mobile populations and the distribution of epidemic risks. ${ }^{2-5}$ Also, the propagation of the most recent global public health threats, SARS, Middle East respiratory syndrome, Ebola, influenza A (H1N1), ZIKV infections and the ongoing COVID-19 pandemic, caused by SARS-CoV-2, was facilitated by the combination of human mobility at different geographical levels. ${ }^{6-8}$

Travel connectivity-based assessments may help understand patterns of travel networkmediated epidemics. ${ }^{9}{ }^{10}$ This approach provides regions and countries with evidence for preparedness and response to potential public health risks based on disease activity in countries with which they are most intensely connected by travel. ${ }^{11}$ However, propagation of an outbreak also depends on the susceptibility of a geographical area and its population to the importation and spread of a pathogen. ${ }^{12}$ A travel connectivity-based approach should therefore take into consideration a country's potential vulnerability and 
capability to respond to epidemics, as well as the situation in its highly connected countries. ${ }^{9}$

Several studies have predicted the pattern of international spread of infectious diseases through global travel, including airborne, vectorborne, foodborne and zoonotic infections. ${ }^{13}{ }^{14}$ However, Oceania and the Pacific Island Countries and Territories (PICTs) are poorly represented in global risk assessments of the introduction and spread of pathogens. Rapid outbreak detection and response in the PICTs are sometimes constrained by the limited availability of efficient data collection and analysis methods. ${ }^{13}$ So far, there has not been any systematic detailed analysis of air travel data in the region in the context of infectious diseases. We address this gap by analysing data on air travel volume under normal travel conditions and providing information on each country's vulnerability to outbreaks. This study aims to determine the risk of (1) introduction of infectious diseases to and from Oceania; (2) spread of infectious diseases within Oceania and (3) spread of infectious diseases between each PICT and their most connected countries. The findings help to identify countries that are high priority for funding and technical support if an outbreak emerges in different countries within Oceania or around the world.

\section{METHODS}

\section{Study setting}

Oceania is composed of 24 countries and territories in the Central and South Pacific Ocean. The continent spans almost $12000 \mathrm{~km}$ from East to West and $6000 \mathrm{~km}$ from North to South, with a total land area of 8.5 million $\mathrm{km}^{2}$. In 2019, the population was 42.6 million, of which 25.5 million lived in Australia, 4.9 million in New Zealand and 12.2 million spread across 22 PICTs (with 8.9 million in Papua New Guinea (PNG) $).{ }^{15}$

The geographical and cultural diversity of the region have contributed to the heterogeneous health and socioeconomic conditions. ${ }^{16}$ Australia and New Zealand lead the continent's economic development with very high human development indices, placing 6th and 14th out of 189 countries in 2018, respectively. ${ }^{16}$ In the same report, Fiji, Palau, Samoa, Tonga and the Republic of Marshall Islands were ranked in the high human development category; The Federated States of Micronesia (FSM), Kiribati and Vanuatu in the medium category; and the Solomon Islands and PNG in the low category. ${ }^{16}$ Due to geography, small size and isolation, several PICTs are among the most vulnerable areas in the world (both economically and environmentally) in terms of natural disasters and disease outbreaks. ${ }^{17}$ In addition, most of their national health systems have limited capacity to conduct surveillance and respond to major outbreaks. ${ }^{17}$

\section{Data sources}

International travel volume data

Data on travel to and from Australia and New Zealand for the year 2018 were obtained from the Australian Bureau of Statistics and Stats NZ websites, respectively. ${ }^{18}{ }^{19}$ Yearly data for all PICTs were obtained from the 2018 report from the United Nations World Tourism Organization (UNWTO) ${ }^{20}$

- Inbound data correspond to arrivals of visitors (tourists and same-day non-resident visitors) at national borders by country of nationality. ${ }^{20}$

- Outbound data refer to the number of residents leaving the country of reference and their destination countries. ${ }^{20}$

The sources included data from all administrative and border control point reports, and also data on the country where most time was spent overseas.

\section{Infectious Disease Vulnerability Index data}

The Infectious Disease Vulnerability Index (IDVI) was used as a measure of each country's vulnerability to outbreaks. This index was selected for the analysis due to its multicomponent design that provides an indicator of disease outbreak outcome based on seven domains: demographic, healthcare, public health, disease dynamics, political domestic, political international and economic. $^{21}$ IDVI scores range from 0 (highest vulnerability) to 1 (greatest capacity) based on a country's capacity to respond to outbreaks. ${ }^{21}$

\section{Analysis}

Australia, New Zealand and 19 PICTs reported inbound and outbound data to the UNWTO in 2018. There were no UNWTO reports for three PICTs with very small populations: the Pitcairn Islands (population 48), Tokelau (1499) and Wallis and Futuna (11 239) and these were excluded from the analysis. ${ }^{20}$

\section{Data extraction and categorisation}

Total travel volumes (number of passengers) for Australia, New Zealand and each PICT were calculated by summing their respective yearly inbound and outbound data in 2018 to provide a measure of overall connectivity between each pair of locations. Total travel volume for Oceania was calculated by aggregating the travel volumes of all countries in the continent.

IDVI data were analysed as four categorical variables based on two vulnerability profiles proposed by the RAND Corporation that included 0 to 0.26 for the most-vulnerable countries, and $\geq 0.82$ to 1.0 for the leastvulnerable countries. ${ }^{21}$ For countries with IDVIs outside these two groups, two more categories were created based on the distribution of the data: intermediate low vulnerability for countries with IDVIs between $\geq 0.50$ and $<0.82$ and intermediate high vulnerability for countries with IDVIs from $<0.50$ to $>0.26$.

\section{Network analysis}

Network analysis was used to represent the degree of connectivity between pairs of locations. The open-source software for graph and network visualisation $\mathrm{Gephi}^{22}$ and the Map of Countries Gephi layout plugin ${ }^{23}$ were used to build travel networks. The networks were formulated 
by creating edges (links) between nodes (countries). Each node in the networks was assigned attributes that determine its uniqueness (identification number and label), size (total travel volume) and position on a map (the countries' geographical location). The colour of the edges represents connections with Australia, New Zealand, the PICTs and different continents outside Oceania. Using the Maps of Countries Gephi layout plugin all nodes were located geographically and overlaid on a world map.

Three sets of travel networks were produced:

- Travel network 'Oceania and its most connected countries': using Oceania as the centre of the network, a travel network was developed using the total travel volumes estimated for the continent and its most connected countries (travel routes with total of $\geq 150000$ inbound and outbound passengers in 2018 were included). For each external country, the colour of the node was used to represent its IDVI to help visualise the country's capacity to prepare for and respond to infectious disease outbreaks.

- Travel networks for "Australia and New Zealand and their most connected countries': two separate networks were built to visualise the risk of infection disease transmission between Australia and its most connected countries, and New Zealand and its most connected countries. Similar to the network created for Oceania, travel routes with $\geq 150000$ total passengers in 2018 were included, and all attributes of the nodes and edges described above were applied.

- Travel networks for 'The PICTs and their most connected countries': using each individual PICT as the centre of a network, travel networks were created using the total travel volume estimates for the PICTs and their most connected countries. Travel routes for strong connections ( $\geq 1000$ passengers) in 2018 were included, and all attributes of the nodes and edges described above were applied. Tuvalu did not report travel routes with more than 1000 passengers in 2018, but a network was created to provide a visual representation of its connection to Australia and New Zealand.

\section{Chord diagram}

Two chord diagrams were created using the chorddiag package in $\mathrm{R}$ software ${ }^{24}$ to visualise 'Connectivity between countries within Oceania'. One Chord diagram includes the five main geographical regions of the continent: Australia, New Zealand, Melanesia, Micronesia and Polynesia. The second chord diagram focused on travel between PICTs. Travel volume is indicated by the width of each chord at its base (on the circle's perimeter).

\section{Patient and public involvement}

It was not appropriate to involve patients or the public in the design, or conduct, or reporting, or dissemination plans of our research.
Table 1 Total travel volumes (inbound plus outbound) and Infectious Diseases Vulnerability Indices (IDVI) for Oceania, Australia, New Zealand and the 19 PICTs in 2018

\begin{tabular}{|c|c|c|c|}
\hline Ranking & & $\begin{array}{l}\text { Total travel } \\
\text { volume in } \\
2018\end{array}$ & IDVI \\
\hline & Oceania & 41219152 & - \\
\hline 1 & Australia & 28299562 & 0.912517 \\
\hline \multirow[t]{2}{*}{2} & New Zealand & 7782497 & 0.916279 \\
\hline & PICTs & & \\
\hline 3 & Guam & 1615225 & - \\
\hline 4 & Fiji & 990625 & 0.567238 \\
\hline 5 & $\begin{array}{l}\text { Northern Mariana } \\
\text { Islands }\end{array}$ & 680782 & - \\
\hline 6 & Papua New Guinea & 431033 & 0.339184 \\
\hline 7 & French Polynesia & 235112 & - \\
\hline 8 & New Caledonia & 220593 & - \\
\hline 9 & Samoa & 208931 & 0.580679 \\
\hline 10 & Cook Island & 176612 & - \\
\hline 11 & Vanuatu & 146032 & 0.490878 \\
\hline 12 & Palau & 128425 & 0.658010 \\
\hline 13 & Tonga & 100931 & 0.630046 \\
\hline 14 & American Samoa & 73852 & - \\
\hline 15 & $\begin{array}{l}\text { Federated States of } \\
\text { Micronesia }\end{array}$ & 46912 & 0.425305 \\
\hline 16 & Solomon Islands & 39156 & 0.370311 \\
\hline 17 & Niue & 12438 & - \\
\hline 18 & Kiribati & 9971 & 0.388403 \\
\hline 19 & Marshall Islands & 9483 & 0.544611 \\
\hline 20 & Nauru & 6675 & - \\
\hline 21 & Tuvalu & 4305 & 0.608741 \\
\hline
\end{tabular}

PICTs, Pacific Island Countries and Territories.

\section{RESULTS}

Total travel volumes for the whole continent, Australia, New Zealand and the 19 PICTs in 2018 are shown in table 1 . Online supplemental material 1 shows the 10 countries with the largest travel volume for each PICT in 2018.

The categorisation of IDVIs showed that within Oceania, Australia and New Zealand were countries classified as least vulnerable countries, six PICTs were categorised as intermediate low vulnerable (Fiji, Marshall Islands, Palau, Samoa, Tonga and Tuvalu) and five as intermediate highly vulnerable (FSM, Kiribati, PNG, Solomon Islands and Vanuatu). There were also nine PICTs that did not have reports of IDVIs, including three territories of the USA (American Samoa, Guam, Northern Mariana Islands (NMI)), three territories of France (French Polynesia, New Caledonia and Wallis and Futuna) and two in 'free association' with New Zealand (Cook Islands and Niue). Nauru is the only fully independent country 


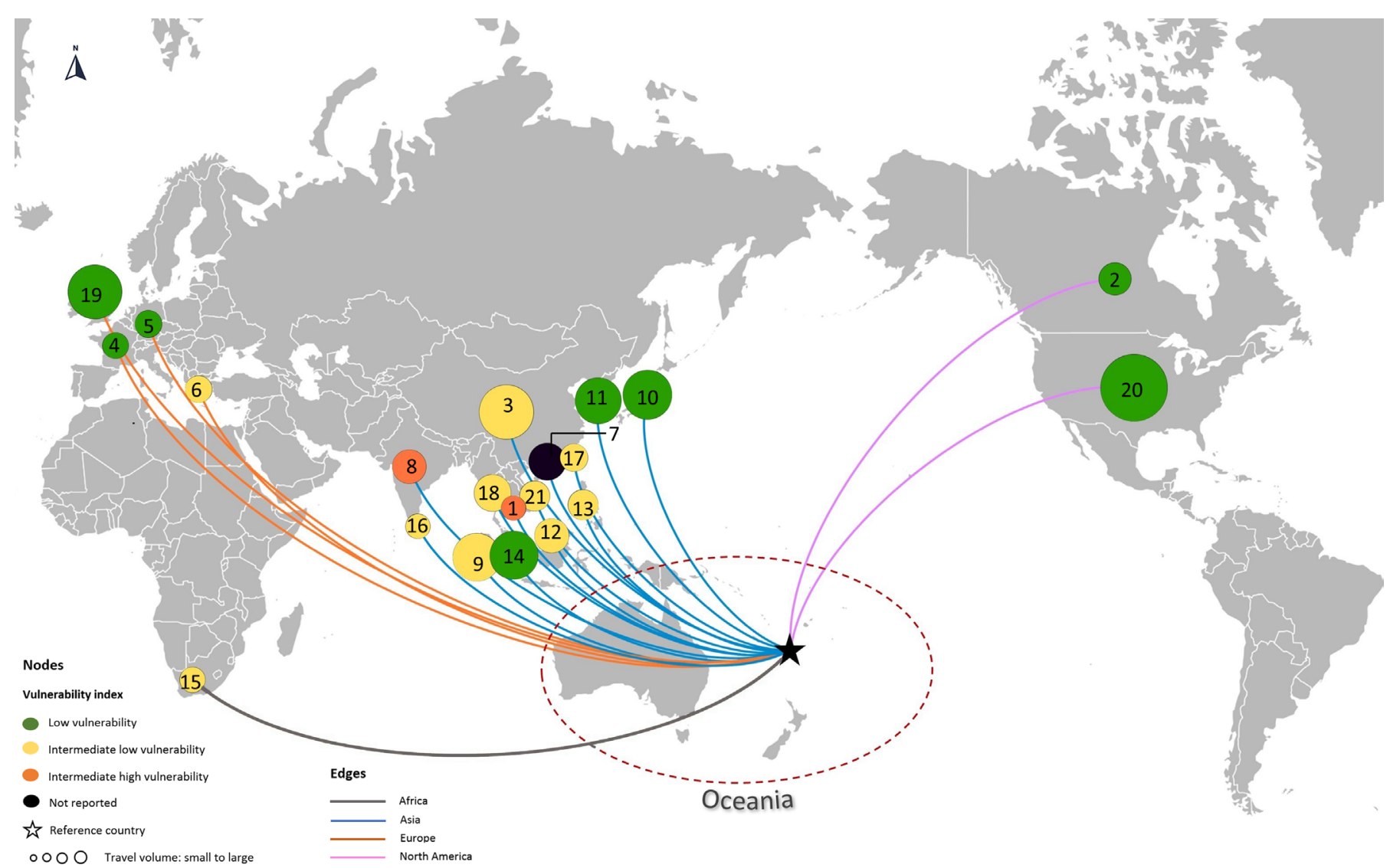

Figure 1 Network: Oceania and its most connected countries in 2018, and each country's Infectious Disease Vulnerability Index. (1) Cambodia, (2) Canada, (3) China, (4) France, (5) Germany, (6) Greece, (7) Hong Kong, China, (8) India, (9) Indonesia, (10) Japan, (11) Republic of Korea, (12) Malaysia, (13) Philippines, (14) Singapore, (15) South Africa, (16) Sri Lanka, (17) Taiwan, (18) Thailand, (19) UK, (20) USA, (21) Viet Nam.

in Oceania that did not have IDVI reports. From all 58 countries included in the networks (countries in Oceania and all connections), $23(39.6 \%)$ were categorised as intermediate low vulnerable, $17(29.3 \%)$ least vulnerable countries and $5(8.6 \%)$ intermediate highly vulnerable countries. Thirteen $(22.4 \%)$ countries did not have IDVI reported. No countries included in the networks were classified as highly vulnerable for outbreaks.

\section{Oceania and its most connected countries}

A total of 21 countries had $\geq 150000$ passenger connections with Oceania in 2018. The networks indicated that Oceania was most connected to countries in Asia (14 countries) followed by Europe (4) and North America (2) (figure 1). There was only one travel route with $\geq 150000$ passengers between Oceania and Africa (South Africa). Based on the travel volume estimates, the top five most connected countries to Oceania were: USA (total travel volume of 3152679 ), China (2 262516 ), the UK (2 228 196), Japan (1 897 767) and Indonesia (1 813 344). Figure 1 shows that 10 of Oceania's most connected countries were classified as intermediate low vulnerable for outbreaks (yellow), eight were low vulnerability countries (green) and only two were intermediate highly vulnerable countries (orange).

\section{Comparison of the most connected countries to Australia and New Zealand}

Australia had travel connections of $\geq 150000$ passengers with 21 countries (figure 2A) while New Zealand had this degree of connection with nine countries (figure 2B). Most of these connections were in Asia. Both countries were also highly connected to Europe, North America and other parts of Oceania. In addition, Australia had a travel route with $\geq 150000$ passengers with South Africa. Australia and New Zealand were most connected to each other. The second and third most connected countries to Australia and New Zealand were the USA (travel volumes of 2151811 and 636 694, respectively) and the UK (1 733 326 and 464947 , respectively). According to the IDVIs categorisation, the most connected countries to Australia and New Zealand were either intermediate low vulnerable (ten and three countries, respectively) or least vulnerable countries (nine and six countries, respectively). India was the only country highly connected to Australia that was classified as intermediate highly vulnerable for outbreaks.

\section{The PICTs and their most connected countries}

For each PICT, the number of country connections with $\geq 1000$ passengers varied greatly (figure 3 ). The PICTs with the highest number of such connections were Fiji (24 

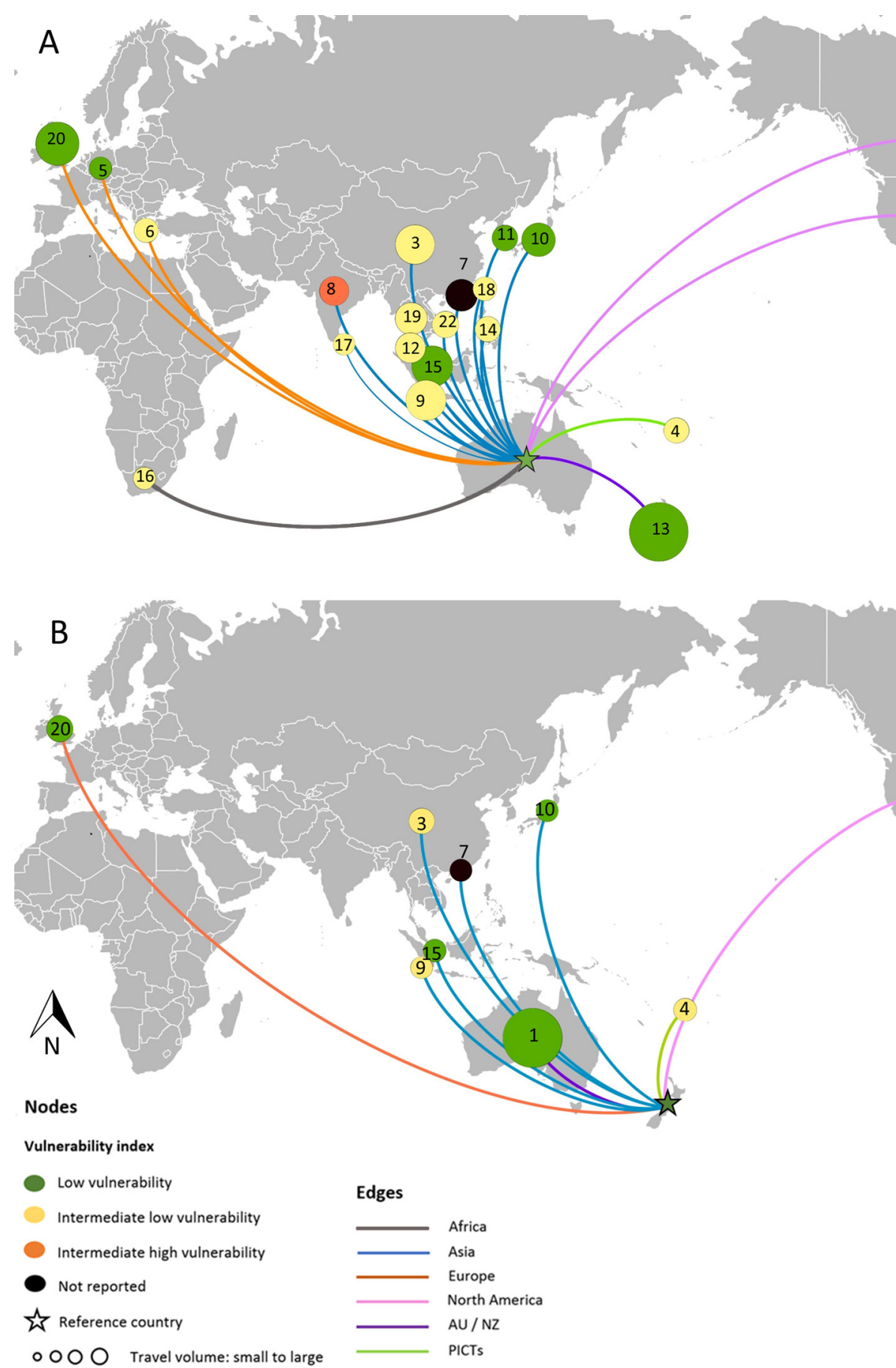

Figure 2 Network: Australia (A) and New Zealand (B) and their most connected countries in 2018, and each country's Infectious Disease Vulnerability Index. (1) Australia, (2) Canada, (3) China, (4) Fiji, (5) Germany, (6) Greece, (7) Hong Kong, China, (8) India, (9) Indonesia, (10) Japan, (11) Republic of Korea, (12) Malaysia, (13) New Zealand, (14) Philippines, (15) Singapore, (16) South Africa, (17) Sri Lanka, (18) Taiwan, (19) Thailand, (20) UK, (21) USA, (22) Viet Nam. PICTs, Pacific Island Countries and Territories.

countries), French Polynesia (20), Guam (15) and PNG (15). The three least connected PICTs were Nauru (with its most connected country being Australia), and Niue and Tuvalu (most connected to Australia and New Zealand). The travel networks in figure 3 also show high variability between the PICTs in the geographical distribution of their international connections. With the exception of Marshall Islands and the NMI, most countries were highly connected to both Australia and New Zealand, or to at least of one of them. The only PICT highly connected to an African country was New Caledonia (with Reunion) while French Polynesia was the only PICT with connections of $\geq 1000$ passengers with South America (Argentina, Brazil and Chile). Cook Islands, Kiribati, Niue and Tuvalu were the only PICTs that had only strong travel connections with least vulnerable countries. Guam was 


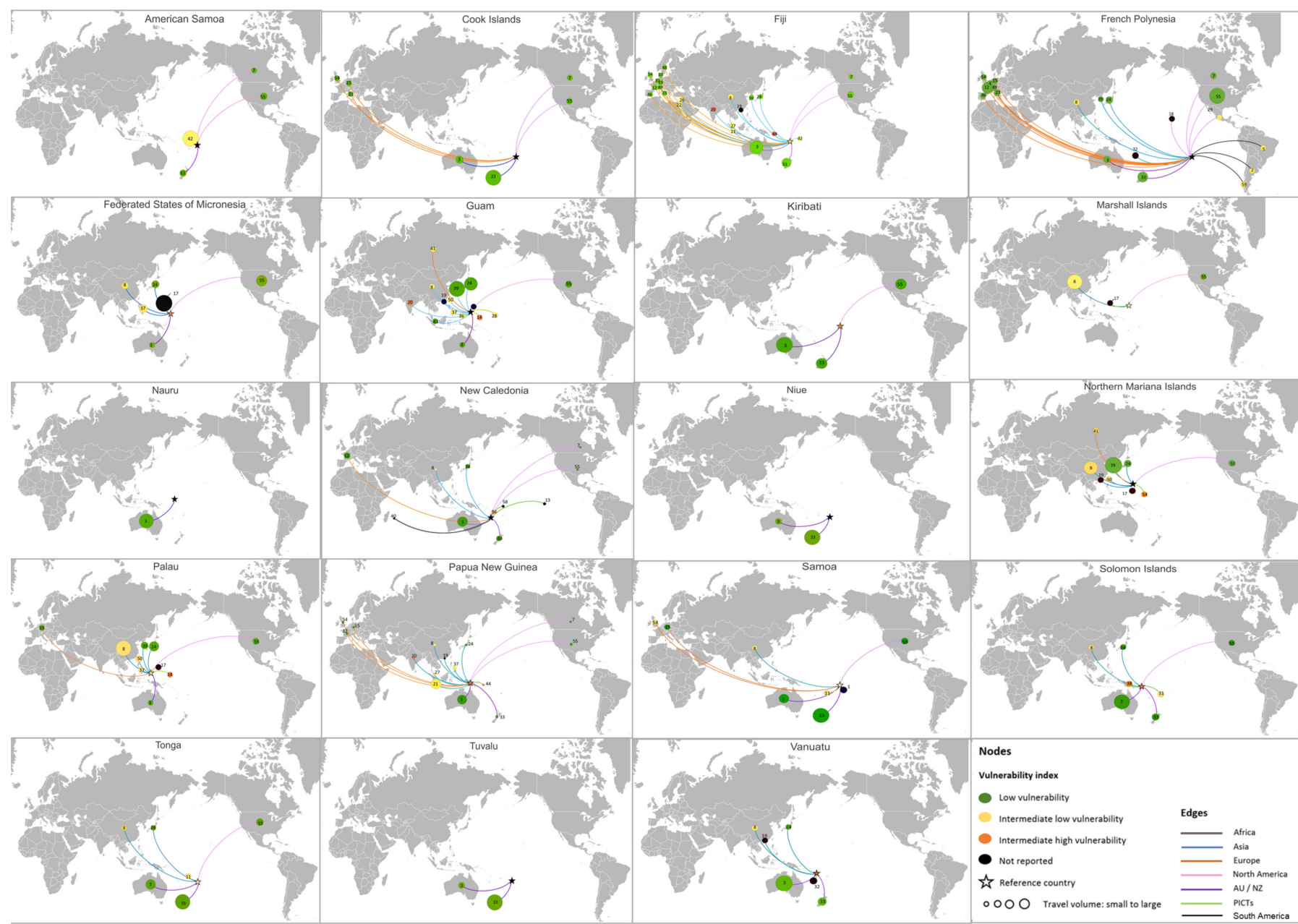

Figure 3 Network: The PICTs and their most connected countries in 2018, and each country's Infectious Disease Vulnerability Index. (1) American Samoa, (2) Argentina, (3) Australia, (4) Belgium, (5) Brazil, (6) Cambodia, (7) Canada, (8) China, (9) Cook Island, (10) Denmark, (11) Fiji, (12) France, (13) French Polynesia, (14) Federated States of Micronesia, (15) Germany, (16) Greece, (17) Guam, (18) Hawaii, (19) Hong Kong, (20) India, (21) Indonesia, (22) Israel, (23) Italy, (24) Japan, (25) Kiribati, (26) Lebanon, (27) Malaysia, (28) Marshall, (29) Mexico, (30) Nauru, (31) Netherlands, (32) new Caledonia, (33) NZ, (34) Nieu, (35) Northern Mariana Islands, (36) Palau, (37) Philippines, (38) Papua New Guinea, (39) Republic of Korea, (40) reunion, (41) Russia, (42) Samoa, (43) Singapore, (44) Solomon Islands, (45) South Africa, (46) Spain, (47) Sri Lanka, (48) Sweden, (49) Switzerland, (50) Taiwan, (51) Thailand, (52) Tonga, (53) Tuvalu, (54) UK, (55) USA, (56) Vanuatu, (57) Viet Nam, (58) Wallis and Futuna, (59) Chile. PICTs, Pacific Island Countries and Territories.

the only PICT connected to more than one intermediate highly vulnerable country (India and FSM).

\section{Connectivity within countries in Oceania}

Figure 4A shows that travel volumes for Australia and New Zealand were extremely high relative to the other countries. The most connected PICTs to Australia and New Zealand include Fiji (highly connected to both countries), PNG (highly connected to Australia), and Cook Islands (highly connected to New Zealand). After excluding Australia and New Zealand from the analysis, figure $4 \mathrm{~B}$ reveals that Guam had the highest total travel volume within the region, while Niue and Nauru reported the lowest. The highest volume connection between individual PICTs was between Samoa and American Samoa (28 063), followed by the connections between Vanuatu and New Caledonia (20 074), and Guam and the NMI (19 325). Interactive versions of the chord diagram plots are available at https://rpubs.com/Angelamcr/748384 (figure 4A) and https://rpubs.com/Angelamcr/748390 (figure 4B).

\section{DISCUSSION}

This study demonstrates the critical role of travel connectivity for helping characterise risks of infectious disease transmission into and within the continent of Oceania. Based on travel volumes alone, infectious diseases in Oceania are most likely to be imported from Asia, followed by Europe and North America. Of countries in Asia, China, Japan and Indonesia clearly represent important potential sources of importation of infectious diseases into Oceania. Other likely sources of importation include the USA and the UK; multiple Oceania countries including Australia, New Zealand and several PICTs 

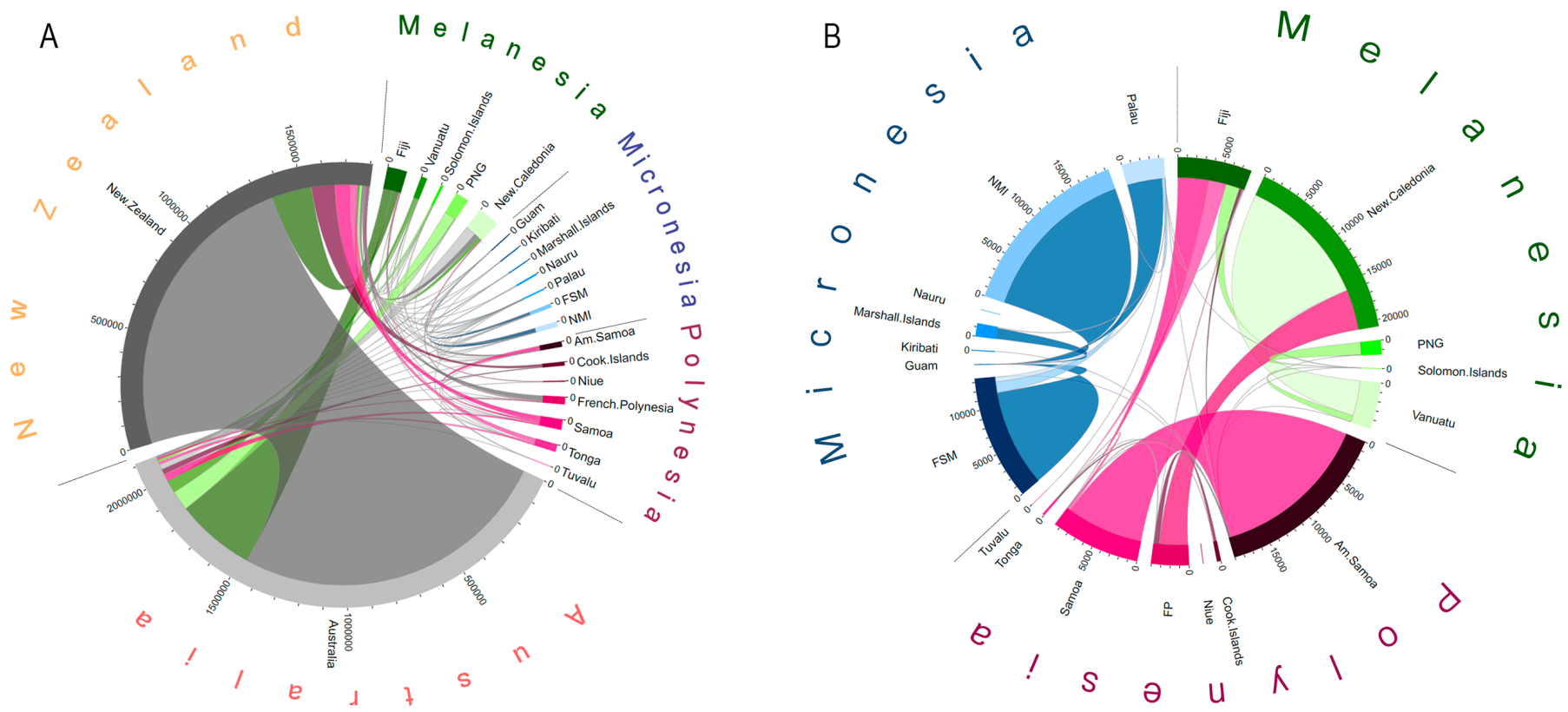

Figure 4 Chord diagram plots of total travel volume flows between countries in Oceania (A) including Australia and New Zealand and (B) without Australia and New Zealand in 2018. Interactive versions of these figures are available at https://rpubs. com/Angelamcr/748384 and https://rpubs.com/Angelamcr/748390.

(Cook Islands, Fiji, French Polynesia, New Caledonia, Palau, PNG and Samoa) were highly connected to the USA and the UK. Our results affirm previous reports on the risk of COVID-19 importation into the PICTs through global air travel..$^{25}$ Although the previous study did not have reports from the UK, the outcomes showed that the highest risk air routes for the importation of SARS-CoV-2 into the region were those from Asia (especially from China, the Republic of Korea, Japan, Singapore) and the USA. ${ }^{25}$

The likelihood of an outbreak spreading between countries in Oceania and Africa are most likely to be initiated by infected passengers coming from or to Australia (highly connected to South Africa), and New Caledonia (highly connected to Reunion). Also, there is a potential threat of epidemic spread between French Polynesia and South America. ZIKV infections were reported sporadically in Africa and Asia until 2007 but emerged in the PICTs with outbreaks in FSM in 2007 and French Polynesia in 2013-2014. ${ }^{26}$ Subsequently, ZIKV transmission was identified in New Caledonia, Vanuatu, Cook Islands and Solomon Islands. ${ }^{26}$ The importation of ZIKV into South America appears to have originated in the PICTs through travellers that attended a sporting event in Brazil in $2014 .^{26}$

SARS-CoV-2 was introduced into Oceania from Wuhan, China, with the first COVID-19 case recorded in Australia on the 25 January $2020 .{ }^{27}$ New Zealand reported its first case from a passenger arriving from Iran on 28 February 2020, while French Polynesia reported the first confirmed case in the PICTs in a traveller returning from France on 7 March 2020. ${ }^{27}$ Although SARS-CoV-2 was mostly introduced into Oceania countries from its most connected countries, travel connectivity is not expected to provide a useful indication of the ongoing pattern of spread because travel restrictions have been so profound during the pandemic. Previous studies and epidemiological reports of the COVID-19 pandemic support the evidence provided in this study about the risk of introduction of pathogens into Oceania from its highly connected countries. ${ }^{28}$ Of note, the USA and the UK, both with high IDVI (ie, low risk of infectious disease outbreak) are currently reporting very high COVID-19 case and mortality rates compared with most countries in the world. This finding indicates that factors considered in the development of IDVI may not be the only determinants of early and effective outbreak response. Political leadership and citizens' adherence to public health recommendations are likely to be also important in determining the short-term and long-term trajectory of an outbreak. Although the IDVI has been extensively used to stratify the potential impact of COVID-19 on different countries, its accuracy has not been reported. ${ }^{9}$ The predictive accuracy of other indices used to indicate a country preparedness and capability are also varied. ${ }^{29}$

Notably there was great variation in the travel networks created for the individual countries within Oceania. Therefore, the risk of importation of pathogens into specific countries depends on the intensity of transmission in their most connected countries. Once a pathogen has been introduced into a country in Oceania, the high variability of connecting routes will also influence the likely patterns of geographical spread within the region. Highly connected routes between countries such as Australia and New Zealand, American Samoa and Samoa, FSM and Guam may be influenced by geographical proximity, and the degree of social and trade connections. Colonial legacies and social and cultural links may also 
play a role in connecting New Caledonia and French Polynesia to France, or American Samoa and other US territories to the USA. Tourism is a major driver of the highly connected routes of Fiji and French Polynesia with other countries in Oceania, North America and Europe.

The Pacific Public Health Surveillance Network has a well-established regional syndromic surveillance system which includes influenza-like illness. ${ }^{30}$ However, this system was established to provide early warning signals or alerts of unusual syndromic activity and requires follow-up laboratory testing to detect novel or emerging pathogens, a capacity that is limited in most PICTs. Therefore, countries with close connections to the PICTs, especially Australia and New Zealand, should be alert to travellers and visitors with symptoms that could be related to an infectious disease and maintain a high index of clinical suspicion even if the disease has not yet been reported from that PICT.

To optimise early detection and control of outbreaks in Oceania, particularly in the PICTs, surveillance activities (eg, access to laboratory diagnosis and monitoring signals on syndromic surveillance) should be prioritised. If an infectious disease with epidemic potential is diagnosed in returned travellers from a PICT, prompt reporting could provide sentinel information and early warning to public health authorities. ${ }^{30}$ This approach increases the potential for facilitating timely interventions to reduce further spread. High-income countries with close connections with the PICTs should continue to provide laboratory and surveillance technical support to reduce the risk of international spread.

The limitations of this study include that it relied on data collected based on nationality rather than the passengers' country of residence, but it is expected that most people reside in their country of citizenship. Also, there was no distinction in the inbound data between connecting and direct travel, which may have an impact on the interpretation of the results as there is probability of exposure during transit at airports. However, the data required to refine this point were not available and are unlikely to make any significant differences to the overall travel patterns identified by our study. Our analyses were based on 2018 travel volumes; although current travel patterns have been significantly affected by travel restrictions, the relative volumes between countries are likely to be similar once international travel resumes. Over time, networks may need to be updated as travel patterns and volumes evolve, or as more accurate indices of outbreak response capability are developed.

\section{CONCLUSION}

Given the exponential growth of international travel over the past two decades, travel connectivity-based approaches are an essential component of epidemic risk assessments to identify vulnerable countries or regions. The results suggest that understanding the connectedness among countries is important in epidemic risk assessments. However, connectivity is not the only factor determining the introduction and potential propagation of an infectious disease outbreak; thus, travel networks should be contextualised and assessed based on the susceptibility of each geographical area to a specific epidemic. The study also demonstrated that there is great heterogeneity between countries in Oceania in the risk of importation of an infectious pathogen into the country. Understanding how an outbreak could spread across international borders may inform and help implement emergency response measures.

Contributors CLL, ACR and LF-K contributed to study design. ACR and LF-K collected the travel data. ACR developed the travel networks with input from CLL and LF-K. ACR, CLL, LF-K, HM and EN provided critical comments and helped in drafting and finalising the manuscript. All authors read and approved the final manuscript.

Funding CLL and LF-K were supported by Australian National Health and Medical Research Council Fellowships (APP1193826 and APP1158469).

Map disclaimer The inclusion of any map (including the depiction of any boundaries therein), or of any geographic or locational reference, does not imply the expression of any opinion whatsoever on the part of BMJ concerning the legal status of any country, territory, jurisdiction or area or of its authorities. Any such expression remains solely that of the relevant source and is not endorsed by BMJ. Maps are provided without any warranty of any kind, either express or implied.

Competing interests None declared.

Patient consent for publication Not required.

Ethics approval Given the study design and the use of publicly available data, no ethical approval was considered necessary.

Provenance and peer review Not commissioned; externally peer reviewed.

Data availability statement Data are available on reasonable request. The data used in the present study are available from the corresponding author on reasonable request.

Supplemental material This content has been supplied by the author(s). It has not been vetted by BMJ Publishing Group Limited (BMJ) and may not have been peer-reviewed. Any opinions or recommendations discussed are solely those of the author(s) and are not endorsed by BMJ. BMJ disclaims all liability and responsibility arising from any reliance placed on the content. Where the content includes any translated material, BMJ does not warrant the accuracy and reliability of the translations (including but not limited to local regulations, clinical guidelines, terminology, drug names and drug dosages), and is not responsible for any error and/or omissions arising from translation and adaptation or otherwise.

Open access This is an open access article distributed in accordance with the Creative Commons Attribution Non Commercial (CC BY-NC 4.0) license, which permits others to distribute, remix, adapt, build upon this work non-commercially, and license their derivative works on different terms, provided the original work is properly cited, appropriate credit is given, any changes made indicated, and the use is non-commercial. See: http://creativecommons.org/licenses/by-nc/4.0/.

ORCID iD

Angela Cadavid Restrepo http://orcid.org/0000-0003-0359-9410

\section{REFERENCES}

1 Oshitani H. Globalization and emerging infectious diseases. Nihon Rinsho 2016;74:1956-61.

$2 \mathrm{Hu} \mathrm{T}, \mathrm{Li}$ J, Carr MJ, et al. The Asian lineage of Zika virus: transmission and evolution in Asia and the Americas. Virol Sin 2019;34:1-8.

3 Ratnam I, Leder K, Black J, et al. Dengue fever and international travel. J Travel Med 2013;20:384-93.

4 Cha GW, Cho JE, Lee EJ, et al. Travel-associated Chikungunya cases in South Korea during 2009-2010. Osong Public Health Res Perspect 2013;4:170-5.

5 Cao-Lormeau V-M, Musso D. Emerging arboviruses in the Pacific. The Lancet 2014;384:1571-2. 
6 de Wit E, van Doremalen N, Falzarano D, et al. Sars and MERS: recent insights into emerging coronaviruses. Nat Rev Microbiol 2016;14:523-34.

7 To KKW, Chan JFW, Tsang AKL, et al. Ebola virus disease: a highly fatal infectious disease reemerging in West Africa. Microbes Infect 2015;17:84-97.

8 Rodríguez-Morales AJ, MacGregor K, Kanagarajah S, et al. Going global - Travel and the 2019 novel coronavirus. Travel Med Infect Dis 2020;33:101578.

9 Gilbert M, Pullano G, Pinotti F, et al. Preparedness and vulnerability of African countries against importations of COVID-19: a modelling study. Lancet 2020;395:871-7.

10 Tian H, Sun Z, Faria NR, et al. Increasing airline travel may facilitate co-circulation of multiple dengue virus serotypes in Asia. PLoS Negl Trop Dis 2017;11:e0005694.

11 Tuite AR, Bhatia D, Moineddin R, et al. Global trends in air travel: implications for connectivity and resilience to infectious disease threats. J Travel Med 2020;27. doi:10.1093/jtm/taaa070. [Epub ahead of print: 14 Jul 2020].

12 Wilson ME. Travel and the emergence of infectious diseases. Emerg Infect Dis 1995;1:39-46.

13 Tatem AJ, Rogers DJ, Hay SI. Global transport networks and infectious disease spread. Adv Parasitol 2006;62:293-343.

14 Field V, Gautret P, Schlagenhauf P, et al. Travel and migration associated infectious diseases morbidity in Europe, 2008. BMC Infect Dis 2010;10:330.

15 Statistics for Development Division (Pacific Community). Population, 2020. Available: https://sdd.spc.int/topic/population

16 United Nations development Programme. Human development report 2019. inequalities in human development in the 21 st century. Briefing note for countries on the 2019 human development report. New York: United Nations development Programme, 2019.

17 Campbell JR. Climate-Change migration in the Pacific. Contemp Pac 2014;26:1-28.

18 Australian Bureau of Statistics. Overseas arrivals and departures, Australia, 2018. Available: https://www.abs.gov.au/ausstats/abs@. nsf/products/961B6B53B87C130ACA2574030010BD05
19 Stats NZ infoshare. International travel and migration - ITM, 2018. Available: http://archive.stats.govt.nz/infoshare/?_ga=2.191802026. 140062572.1597806192-913768299.1597806192

20 United Nations World Tourism Organization. UNWTO tourism statistics, 2020. Available: https://www.e-unwto.org/toc/unwtotfb/ current

21 Moore M, Gelfeld B, Okunogbe A, et al. Identifying future disease hot spots: infectious disease vulnerability index. Rand Health Q 2017;6:5.

22 Bastian M, Heymann S, Jacomy M. Gephi: an open source software for exploring and manipulating networks. Third International $A A A$ conference on weblogs and social media 20092009.

23 Levallios C. Map of countries, Gephi layout Plugin. 1.0. Lyon, France; 2012.

24 R Core Team. R: a language and environment for statistical computing. $\mathrm{R}$ foundation for statistical computing, Vienna, Austria 2019. Available: https://www.R-project.org/

25 Craig AT, Heywood AE, Hall J. Risk of COVID-19 importation to the Pacific Islands through global air travel. Epidemiol Infect 2020;148:e71.

26 Musso D. Zika virus transmission from French Polynesia to Brazil 2015.

27 World Health Organization. WHO coronavirus disease (COVID-19) Dashboard, 2020. Available: https://covid19.who.int/?gclid=CjwK CAjwnef6BRAgEiwAgv8mQbJKa1DZpcU3hheXQLmmVKAEYVPj vAQF5tFy3xV81iCMFcBZNtJyBBoCidOQAvD_BwE

28 The Department of Health. Coronavirus disease (COVID-19) epidemiology reports, Australia, 2020, 2020. Available: https:// www1.health.gov.au/internet/main/publishing.nsf/Content/novel_ coronavirus_2019_ncov_weekly_epidemiology_reports_australia 2020.htm

29 Abbey EJ, Khalifa BA, Oduwole MO. The global health security index is not predictive of coronavirus pandemic responses among organization for economic cooperation and development countries. medRxiv 2020.

30 SPS Public Health Division. Pacific public health surveillance network, 2020. Available: https://phd.spc.int/programmes/ surveillance/pphsn 